\title{
Natural Ventilation in Isolated Subsurface Structures in the Infrastructure: A Review
}

\author{
Thomas Neil McManus ${ }^{1,2} \&$ Assed N. Haddad \\ ${ }^{1}$ NorthWest Occupational Health \& Safety, North Vancouver, Canada \\ ${ }^{2}$ Programa de Pós-Graduação, Universidade Federal Fluminense, Niterói, Brazil \\ ${ }^{3}$ Escola Politécnica, Universidade Federal do Rio de Janeiro, Rio de Janeiro, Brazil \\ Correspondence: Thomas Neil McManus, North West Occupational Health \& Safety, North Vancouver, BC, \\ V7K1P3, Canada. Tel: 604-980-8512. E-mail: nwohs@mdi.ca
}

Received: April 12, 2019

Accepted: April 24, 2019

Online Published: May 10, 2019

doi:10.5539/enrr.v9n2p61

URL: https://doi.org/10.5539/enrr.v9n2p61

\begin{abstract}
The subsurface infrastructure contains many types of structures. Some are networked together in open systems while others are completely independent from each other. This study provides a summary of findings concerning ventilation induced by natural forces from reports published in the literature + additional unreported information concerning isolated subsurface structures. Isolated subsurface structures meet criteria for classification as confined spaces. Isolated subsurface structures experience two-way exchange of the internal atmosphere with the external atmosphere when the manhole cover or access hatch contains one or more openings. This finding is not appreciated by current practitioners of occupational health and safety knowledgeable in the area of confined spaces. Presently identified factors influencing ventilation induced by natural forces include the number/area of openings in the manhole cover, differences in temperature between the interior airspace and the external atmosphere, and air movement along the surface of the ground. Additional factors could include size or number of individual openings, placement of openings in the manhole cover or hatch, shape of the openings, and shape of the path followed during air exchange. In some cases, application of additional analysis provides information contained in the data but not presented in these documents. Demonstrating and understanding the interaction between these factors will enable optimization of design to maximize the rate of air exchange. Optimizing the rate of air exchange is essential to minimizing to the extent possible the risk posed to passersby and to workers engaged in preparation for entry and work inside these structures.
\end{abstract}

Keywords: Air Exchange, Confined Space, Isolated Subsurface Structure, Infrastructure, Ventilation Induced By Natural Forces

\section{Introduction}

\subsection{The Atmosphere in Isolated Subsurface Structures}

The subsurface infrastructure contains many types of structures. Some of these are networked together in open systems while others are completely independent from each other. Open systems include inter-building utility tunnels and vaults, the wastewater collection system (stormwater and sanitary), the underground electrical system, and possibly vaults and manholes in the telecommunication system. Open systems distinguish themselves from isolated structures through interconnection by pipe or duct between vaults and manholes that enable homogenization of the atmosphere in the airspace of the system through unhindered movement. That is, contamination introduced in one location can spread throughout the system. Systems that contain isolated subsurface structures (Figure 1) include the potable water system, the fuel gas distribution system and district hot water and steam heating systems.

Ventilation of subsurface structures and in particular, isolated structures is an important concern. To illustrate, explosion and fire pose major known risks in subsurface vaults in the underground electrical system. Hundreds of these events occur every year in North America (IEEE, 2015). Approximately 75\% are fueled by chemical products introduced as liquids through openings in manhole and hatch covers as opposed to electrically caused by gases emitted from insulation on cable during thermal degradation. These events date back to 1911 in older parts of Rio de Janeiro and Sao Paulo, Brazil (Polonini, 2016). 


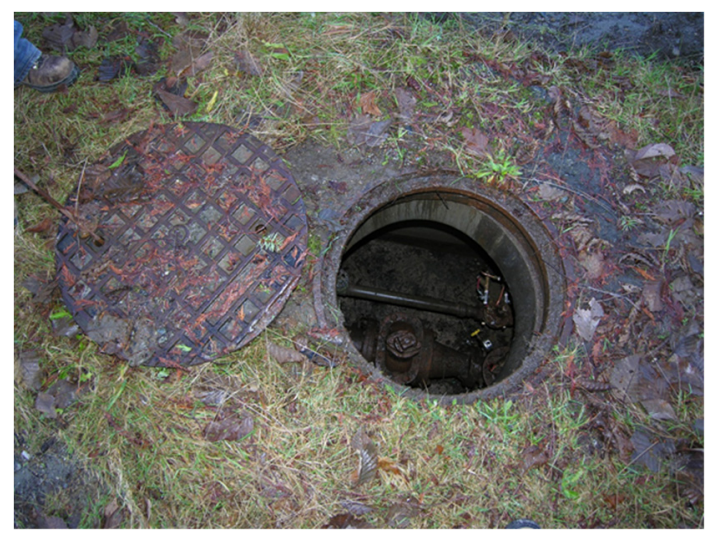

Figure 1. An example of an isolated subsurface structure. This figure shows the interior of an isolated subsurface chamber in the potable water system that contains a pressure-reducing valve. This chamber is entered infrequently. Air quality in the airspace depends on exchange involving the openings in the manhole cover

There are many other types of atmospheric hazards documented in these spaces starting with oxygen deficiency and atmospheres contaminated by chemical substances (McManus, 1998). This concern receives little discussion in the published technical literature despite the fact that the subsurface infrastructure worldwide contains many of these structures and that fatal overexposures occur routinely. These structures can remain undisturbed for long periods of time as illustrated in Figure 1. These structures meet requirements for classification as confined spaces.

McManus \& Haddad (2018) reviewed recent fatal incidents involving hazardous atmospheric conditions and various types of confined spaces. A consistent theme in all of these incidents was absence of a defined path for exchange of air between the external atmosphere and the airspace of the structure. Access manhole covers and hatch covers lacked openings through which exchange of the internal atmosphere with the external atmosphere could occur. Without adequate ventilation, the internal atmosphere is at risk of becoming oxygen-deficient through chemical oxidation of susceptible materials and surfaces and biological oxidation through growth of microorganisms on organic debris that has entered the structure. Airborne contamination occurs through metabolism by microorganisms of organic debris that enters the structure, evaporation of residual contents and volatile liquids that enter through accidental spillage or deliberate disposal into openings in the manhole cover, and chemical processes.

Informal surveys of opinion of current practitioners including those formally educated in occupational health and safety and confined spaces in particular indicate that they believe that ventilation of these structures does not occur. This opinion is easy to formulate. There is no technical information and discussion about the subject. There is no readily available published literature. There is no obvious emission from openings in manhole or hatch covers except when an emergency situation such as mentioned above has developed. There also is no mechanism obvious to the senses through which ventilation of these structures could occur. Ventilation induced by natural forces is not a topic of discussion in the curriculum. Hence, there is likely to be complete absence of knowledge and understanding about ventilation of isolated subsurface structures into which people will enter and work. Work involving confined spaces is solely regulation-driven based on fatal accidents that have occurred (McManus, 1998). There is no apparent effort to study the situation so as to become able to ameliorate it through application of scientific principles and knowledge.

\subsection{Ventilation Principles}

Subsurface isolated structures containing one or more openings through which air exchange, entry of supply air and removal of exhaust air could occur, are basically boxes, as are rooms and other types of structures in which study of ventilation has occurred. Equation 1 provides the generalized mathematical model that describes the accumulation and dilution of a contaminant in the airspace of a room (Burgess et al., 1989; AIHA, 2009). Equation 2, Equation 3 and Equation 4 show the impact of variation of conditions on Equation 1. Equation 1 contains terms for concentration $\left(\mathrm{C}_{1}\right.$ and $\left.\mathrm{C}_{2}\right)$ at different times $\left(\mathrm{t}_{1}\right.$ and $\left.\mathrm{t}_{2}\right)$, generation $(\mathrm{G})$ in the space during the period of measurement, volumetric flow $(\mathrm{Q})$, and volume of the space $(\mathrm{V})$, all in consistent units. 


$$
\mathrm{C}_{2}=\frac{1}{\mathrm{Q}}\left(\mathrm{G}-\left[\mathrm{G}-\mathrm{QC}_{1}\right] \mathrm{e}^{-\frac{\mathrm{Q}\left(\mathrm{t}_{2}-\mathrm{t}_{1}\right)}{\mathrm{V}}}\right)
$$

Application of Equation 1 presumes that dilution air at volumetric flow (Q) entering the space contains negligible contamination; generation of contaminant in the space $(\mathrm{G})$ occurs at constant rate; air exchange occurs through defined path(s); and that mixing of the contaminant with air in the space and incoming uncontaminated air at volumetric flow (Q) occurs completely, thoroughly and rapidly. The quantity $\mathrm{Q} / \mathrm{V}$ is the same as air exchanges per unit of time. Hence, this links the intuitive concept to the mathematical one.

A major requirement of the equation is the presumption of perfect mixing of incoming air with resident air (McManus, 2000). That is, the concentration of contaminant is uniform throughout the space at the two times, $t_{1}$ and $t_{2}$. This means that concentrations, $C_{1}$ and $C_{2}$ are really averages. The only way for this condition to occur in a real situation in the airspace of an isolated subsurface structure would be involvement of natural forces such as temperature differences and surface wind flow to promote mixing and exchange. In theory, these processes can occur through the instantaneous, continuous mixing of uncontaminated air from outside the space with the contaminated air inside to maintain uniform the concentration of contaminants within the space during each increment of change. This likely is difficult to achieve in a real-world structure.

When $\mathrm{G}=0$, the continuous process of supply, instantaneous mixing and expulsion of contaminated air decreases the concentration of contaminants to zero (Equation 2). Again, the conditions and limitations mentioned previously apply to this simplification of equation 1 .

$$
\mathrm{C}_{2}=\mathrm{C}_{1}\left(\mathrm{e}^{-\frac{\mathrm{Q}\left(\mathrm{t}_{2}-\mathrm{t}_{1}\right)}{\mathrm{V}}}\right)
$$

Equation 2 could apply during ventilation of a confined space by natural forces or pre-entry preparation of a confined space using mechanical ventilation or natural forces to remove existing contamination or following some work activity in which generation of contamination stopped.

The second simplification (Equation 3) involves generation of a contaminated atmosphere in a space where the starting concentration was zero $\left(\mathrm{C}_{1}=0\right)$ at $\mathrm{t}_{1}=0$. The resulting concentration $(\mathrm{C})$ at any time $\mathrm{t}$ is given by:

$$
C=\frac{G\left(1-e^{-\frac{Q t}{V}}\right)}{Q}
$$

Work activities in which Equation 3 could apply include painting and the application of coatings where the vapor is rapidly dispersed into the airspace. Note that concerns discussed previously apply here also.

The third simplification occurs where generation of contamination $(G>0)$ and ventilation occurs until a maximum is reached. This is the equilibrium condition.

$$
C_{\max }=\frac{G}{Q}
$$

Without experimental study, the knowledge needed to harness and optimize the process does not exist. Optimized ventilation of these structures therefore is essential to minimize the concentration of contamination in the airspace of the structure and thereby to minimize risk to passersby walking on sidewalks and roadways on top of these structures and workers required to open, to enter and to work in them. Workers experience initial contact with the atmosphere in the airspace during preparation for entry. Exchange of the atmosphere in the airspace of the structure with the external atmosphere can occur when the manhole cover or hatch is first opened. Instruments used for entry into confined spaces in the infrastructure do not necessarily warn about contaminants in the atmosphere in the airspace due to insensitivity of sensors. 


\section{Method}

Articles relevant to this study were identified through Internet search engines and obtained for review. Contents and findings were examined for relevance to this study and additional information not extracted from the data by the original investigators. This data and additional comment are presented here for discussion.

\section{Results}

The literature contains little published information about even the possibility of ventilation induced by natural forces in isolated subsurface structures. What information does exist has become available for inquiry only because of online indexing of historic documents now discoverable through Internet search engines. Without the availability of online indexing and transfer to electronic media, invaluable records from the past would be lost to present inquiry.

\subsection{Bureau of Mines, 1936 to 1940}

Work performed by investigators at the Bureau of Mines in the 1930s while sparse does contain information useful to this enquiry not mentioned by the authors. The focus of this work was to investigate the occurrence ventilation induced by natural forces in subsurface structures belonging to electrical and gas utilities in the Boston area. The investigators published a series of reports related to cast-in-place concrete manholes built for testing purposes (BM, 1936; BM, 1937; BM, 1938; BM, 1940). The manholes were constructed outdoors and thus were subject to weather conditions. The top of the manhole cover was installed slightly above grade. This configuration is not typical in real-world installations at this time. At this time, the rim of the casting in which the manhole cover rests, usually is at grade level. The result is that the manhole cover usually is at or slightly below grade. The latter geometry minimizes problems with tires of vehicles and the shoes of pedestrians. A raised manhole cover also has the potential to influence movement of air at ground level in a manner that is not consistent with movement across current real-world manhole covers. Movement of air at ground level due to wind and movement of vehicles are influences that can affect natural ventilation involving the airspace of isolated subsurface structures.

The strategy employed in these investigations was to create a well-mixed equilibrated airspace, as described in Equation 4, containing a constant (equilibrium) concentration of injected gas (BM, 1936; BM, 1937; BM, 1938; BM, 1940). Investigators previously had devised a method for assessing ventilation in a room of known volume and from this derived a formula for assessing ventilation in isolated manholes (BM, 1923). This strategy depended on measurement of the rate of delivery of gas into the airspace and measurement of concentration at known intervals to confirm constancy. The concentration of introduced gas reached a maximum when the amount escaping equaled the amount introduced. The maximum concentration developed in about 4 hours (BM, 1936). Gas sampling and temperature measurement occurred at three positions in the centre of the horizontal cross-section: $30 \mathrm{~cm}$ ( 12 inches) below the top; mid height; and $30 \mathrm{~cm}$ above the bottom.

Air speed was measured using a three-cup anemometer. The position of the anemometer in the initial report (1.5 $\mathrm{m}$ above the surface of the manhole cover) was considerably above the surface (BM, 1936). Surface air movement could be considerably different from that measured at higher levels. The investigators repositioned the anemometer to $0.75 \mathrm{~m}(2.5 \mathrm{ft})$ above the manhole cover in subsequent investigations (BM, 1937; BM, 1938; BM, 1940). Positioning the anemometer to obtain accurate readings of surface air movement was very important for understanding the observations from these investigations. The investigators remarked early in the project about the perceived influence of surface wind flow on results (BM, 1936; BM, 1937; BM, 1940). Temperature measurement occurred inside and outside the vault. The investigators did not comment about temperature in the reports.

In these investigations, the boundary surfaces of the structure and the manhole cover formed the box described in Equation 1. Inflow of uncontaminated air occurred through opening(s) in the manhole cover. Inflow of gas occurred through the supply piping oriented to ensure a constant concentration inside the airspace. Outflow of diluted gas + air occurred through opening(s) in the manhole cover.

This configuration is not strictly the same as that in a real-world isolated subsurface structure. In essence, this was an open push-pull system operating at a slight pressurization. Slight pressurization was necessary to deliver feed gas into the structure through the distribution piping and to induce mixing with the atmosphere. This occurred in response to the slight vacuum created by removal of the atmosphere from the airspace at the top of the structure through the opening(s) in the manhole cover. Ventilation of a subsurface structure containing an initial fixed concentration and no replacement $(\mathrm{G}=0)$ as occurs naturally, is the subject of an additional article in this series (manuscript submitted for review, not yet cited). 


\subsubsection{Bureau of Mines, 1936}

The first investigation examined the relationship between the number and area of openings in the manhole cover and ventilation rate in a cast-in-place manhole (BM, 1936). The volume of the structure (Figure 2) was $74.1 \mathrm{ft}^{3}$ $\left(2.1 \mathrm{~m}^{3}\right)$. The manhole cover obtained from the manufacturer contained 6 openings positioned equally around the circumference. Increasing the number of openings (area of openings) in the manhole cover from 1 upward produced an approximately linear relationship between ventilation rate (air changes/day) and area of ventilation openings per volume of airspace in the manhole, expressed as $\mathrm{cm}^{2} / \mathrm{m}^{3}$ or in $/ 100 \mathrm{ft}^{3}$.

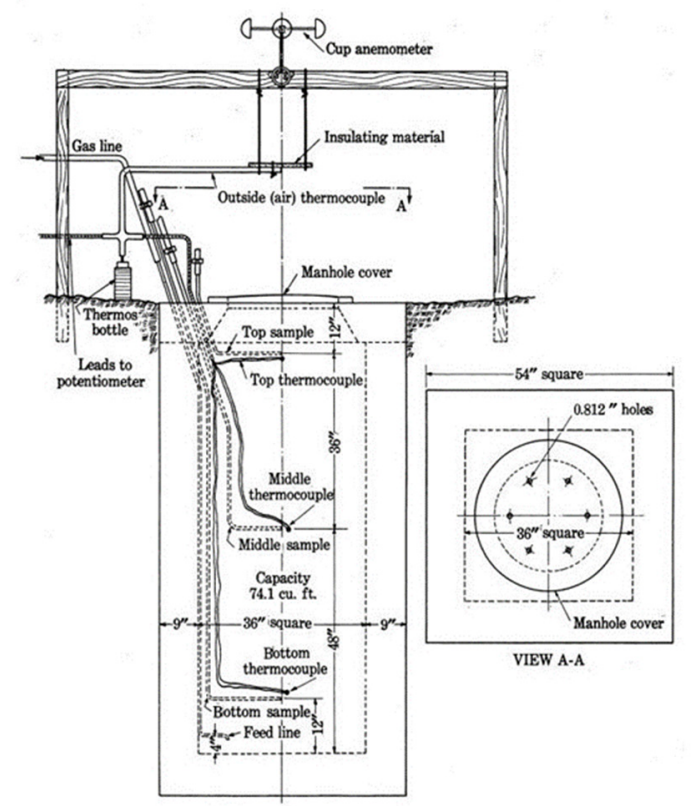

Figure 2. Test manhole prepared for investigation by the Bureau of Mines

This investigation provided critically important observations not emphasized in the report. The first was demonstration that air exchange occurs through a single opening in a manhole cover. The investigators did not indicate or emphasize the importance of this observation. The occurrence of ventilation through a single opening is not an intuitive concept and is not known to present-day practitioners in occupational health and safety because of the difficulty in conceptualizing the mechanism. Visualization of the mechanism of ventilation through video recording is the subject of a subsequent article in this series (manuscript submitted for review, not yet cited).

Air in the external atmosphere must enter and contaminated air in the airspace must exit through the same opening. This observation confirms within the limits of the push-pull system used by the investigators that ventilation of isolated subsurface structures does occur as a naturally occurring process. This process provides no obvious cues to the senses, hence the reason for lack of appreciation of the process in the present era. The investigators did not determine or indicate the mechanism through which air exchange through the single opening and mixing in the airspace were occurring.

The second concept of importance was the number of openings. Table 1 contains data from the report by investigators at the Bureau of Mines (BM, 1936). Ventilation rate increased as the area of the opening(s) increased. Ventilation effectiveness (ventilation rate/area of openings) was not consistent and decreased prior to levelling out as the number of openings increased (Figure 3). Greatest ventilation effectiveness occurred up to 2 openings. Ventilation effectiveness decreased beyond 2 openings and became approximately constant regardless of the number of openings. This information not discussed in the original report argues that manhole covers should have a minimum of 2 openings in order to promote ventilation induced by natural forces. Two openings in manhole covers opposed to each other are routine in many applications but not universal. 
Table 1. Ventilation Parameters Calculated from Data in RI 3307 (BM, 1936)

\begin{tabular}{llllllll}
\hline Number & Opening Area & Exchange Rate & \multicolumn{2}{l}{ Ventilation Rate } & \multicolumn{3}{l}{ Ventilation Effectiveness } \\
\hline \multirow{3}{*}{1} & $\mathrm{in}^{2}$ & $124 \mathrm{~h}$ & $\mathrm{ft}^{3} / 24 \mathrm{~h}$ & $\mathrm{ft}^{3} / \mathrm{min}$ & $\mathrm{L} / \mathrm{min}$ & $\left(\mathrm{ft}^{3} / \mathrm{min}^{2} / \mathrm{in}^{2}\right.$ & $\left(\mathrm{L} / \mathrm{min}^{2} / \mathrm{cm}^{2}\right.$ \\
2 & 0.52 & 1.92 & 142 & 0.099 & 2.80 & 0.19 & 0.83 \\
4 & 1.04 & 2.37 & 176 & 0.12 & 3.40 & 0.12 & 0.53 \\
& 2.07 & 3.06 & 227 & 0.16 & 4.53 & 0.077 & 0.34 \\
6 & 3.11 & 2.94 & 218 & 0.15 & 4.25 & 0.048 & 0.21 \\
12 & 5.76 & 23.20 & 453 & 0.16 & 4.53 & 0.050 & 0.22 \\
24 & 11.1 & 15.6 & 1156 & 0.80 & 22.6 & 0.072 & 0.24 \\
48 & 21.7 & 20.1 & 1489 & 1.03 & 29.1 & 0.047 & 0.32 \\
\hline
\end{tabular}

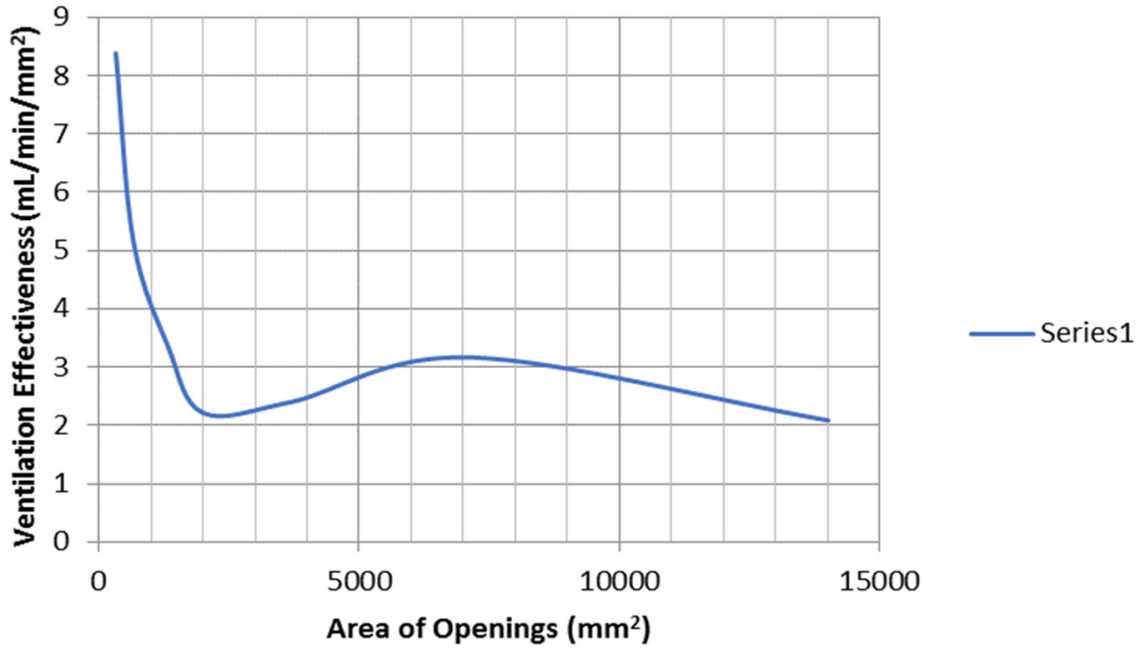

Figure 3. Plot of ventilation effectiveness (efficiency) versus area of openings in the manhole cover. Greatest efficiency of exchange occurs when 1 or 2 openings are present in the manhole cover

\subsubsection{Bureau of Mines, 1937}

The second investigation examined the relationship between volume of the airspace, reflecting different cross-sectional area and depth, and ventilation rate (BM, 1937). This investigation showed that the ventilation rate increased for manholes containing larger airspaces as the area of the openings in the manhole cover increased (BM, 1937). The results did not show any influence from volume or shape of the manhole. The results also showed that when expressed as ventilation rate (air changes/day)/(area of ventilation openings)/(volume of the airspace), (air changes/day) $/ \mathrm{cm}^{2} / \mathrm{m}^{3}$ or (air changes/day) $/ \mathrm{in}^{2} / 100 \mathrm{ft}^{3}$, air exchange was about the same regardless of the volume or shape of the manhole. The tests warranted the general conclusion that the ventilation or air exchange rate increases as the area of openings in the manhole cover increases and is proportional to the area of the openings in the cover. That is, the area of the openings was by far the most important factor that affected ventilation.

\subsubsection{Bureau of Mines, 1938}

The third investigation examined the role of air velocity across the openings in the manhole cover (BM, 1938). The usual source of air velocity above the openings in a manhole cover is the wind and flow induced by movement of vehicles. The investigators had observed in previous tests that the wind exerted considerable influence over the ventilation rate. In this investigation, the investigators embedded the bottom surface of a wind tunnel around the manhole cover in order to provide precise control over air velocity above the openings.

Results from this study indicated that increasing the velocity of air moving along the surface of the manhole cover from 0 to $4.5 \mathrm{~m} / \mathrm{s}(10 \mathrm{mi} / \mathrm{hr})$ irrespective of the area of the openings increased the average ventilation rate by $57 \%$ (BM, 1938). Air velocity has a marked impact on ventilation rate. However, there was no definite relationship between percent increase in ventilation rate due to air velocity across the manhole cover and area of 
openings. The pattern of real-world air motion close to grade level currently is unstudied and may change in speed and to some extent, direction, in a manner undetectable by the cup anemometer. Air motion along the ground is the subject of one of the subsequent articles in this series (manuscript submitted for review, not yet cited).

\subsubsection{Bureau of Mines, 1940}

The fourth investigation examined the role of external vertical ducts connecting the airspace in the manhole with openings at grade (Figure 4) on ventilation induced by natural forces (BM, 1940). One opening into the manhole was near the base and the other near the top. The ducts were 6 in $(15 \mathrm{~cm})$ in diameter with a surface area of $28.3 \mathrm{in}^{2}$ $\left(183 \mathrm{~cm}^{2}\right)$. The first six of the openings in the manhole cover had diameter of $0.812 \mathrm{in}(2.06 \mathrm{~cm})$ and surface area of $0.52 \mathrm{in}^{2}\left(3.35 \mathrm{~cm}^{2}\right)$ each (BM, 1936). Additional openings drilled through the manhole cover had diameter of $0.75 \mathrm{in}$ $(1.91 \mathrm{~cm})$ and surface area of $0.44 \mathrm{in}^{2}\left(2.8 \mathrm{~cm}^{2}\right)$. The volume of the manhole was $166.7 \mathrm{ft}^{3}\left(4.72 \mathrm{~m}^{3}\right)$. This is the volume of one exchange of air from the airspace of the structure.

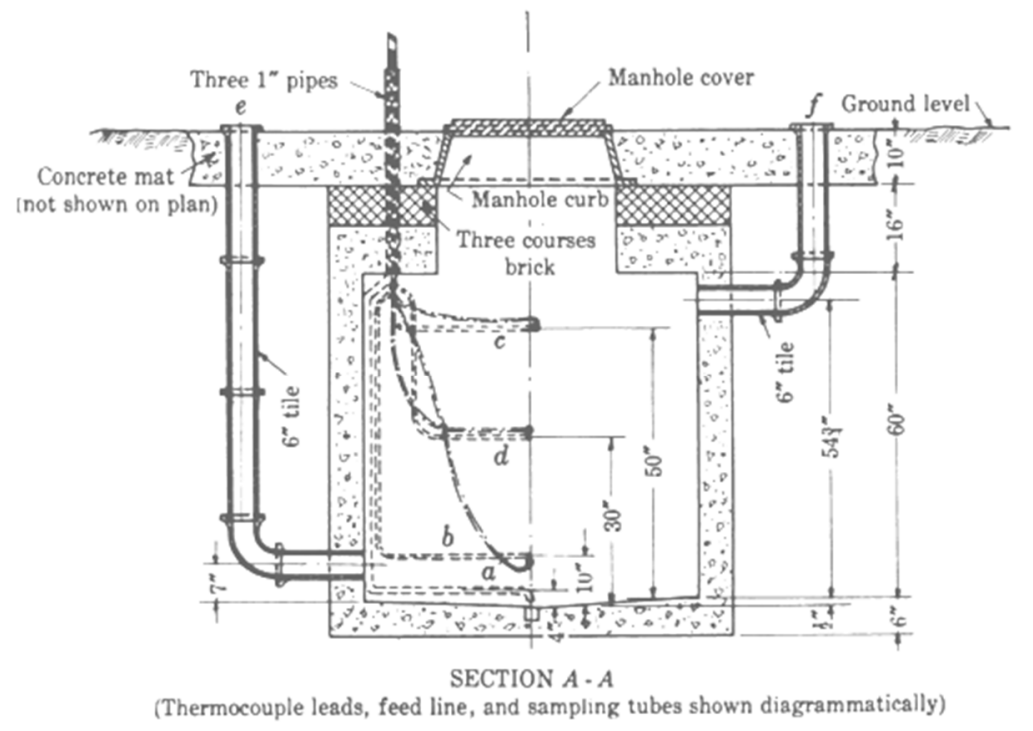

Figure 4. Second manhole prepared for investigation by the Bureau of Mines. Note the supplemental ventilation pathways through the external piping

Table 2. Relationship between Openings to Grade and Manhole Ventilation

\begin{tabular}{|c|c|c|c|c|c|c|c|}
\hline \multicolumn{2}{|c|}{ Manhole Cover } & \multirow{2}{*}{\multicolumn{3}{|c|}{$\begin{array}{l}\text { Duct } \\
\text { Level }\end{array}$}} & \multirow{2}{*}{$\begin{array}{l}\text { Total } \\
\text { Ventilation }\end{array}$} & \multicolumn{2}{|l|}{ Ventilation } \\
\hline \multirow[t]{3}{*}{ Holes } & \multirow[t]{2}{*}{ Area } & & & & & & \\
\hline & & $\mathrm{L}$ & $\mathrm{U}$ & Area & Area* & Rate & Effectiveness \\
\hline & $\mathrm{in}^{2}$ & & & $\mathrm{in}^{2}$ & $\mathrm{in}^{2} / 100 \mathrm{ft}^{3}$ & exchange/day & exchange/day $/ \mathrm{in}^{2} / 100 \mathrm{ft}^{3}$ \\
\hline 1 & 0.52 & NA & NA & NA & 0.70 & 1.92 & 2.74 \\
\hline 0 & NA & 1 & 0 & 28.3 & 16.95 & 2.3 & 0.14 \\
\hline 3 & 1.56 & NA & NA & NA & 0.94 & 2.4 & 2.55 \\
\hline 6 & 3.12 & NA & NA & NA & 1.87 & 2.6 & 1.39 \\
\hline 0 & NA & 0 & 1 & 28.3 & 16.95 & 3.9 & 0.23 \\
\hline 12 & 5.76 & NA & NA & NA & 3.45 & 4.3 & 1.25 \\
\hline 1 & 0.52 & 1 & 0 & 28.3 & 17.27 & 4.9 & 0.28 \\
\hline 24 & 11.0 & NA & NA & NA & 6.62 & 5.5 & 0.83 \\
\hline 48 & 21.6 & NA & NA & NA & 13.04 & 11.3 & 0.87 \\
\hline 3 & 1.56 & 1 & 0 & 28.3 & 17.90 & 12.8 & 0.72 \\
\hline 6 & 3.12 & 1 & 0 & 28.3 & 18.80 & 20 & 1.06 \\
\hline 12 & 5.76 & 1 & 0 & 28.3 & 20.42 & 40.7 & 1.99 \\
\hline 24 & 11.0 & 1 & 0 & 28.3 & 23.62 & 85.8 & 3.63 \\
\hline 0 & NA & 1 & 1 & 56.6 & 33.90 & 92.1 & 2.72 \\
\hline 48 & 21.6 & 1 & & 28.3 & 29.95 & 132. & 4.41 \\
\hline
\end{tabular}

Note: * the area is corrected to the basis of common volume of the structure of $100 \mathrm{ft}^{3}$. 
Table 2 restates the results obtained during these tests (BM, 1940) and the result for the single opening provided in the first report (BM, 1936) in a manner that enables further exploration of the data. The lowest ventilation rate occurred when the duct openings were sealed and the manhole cover contained a single opening. The rate of exchange increased gradually when additional openings were present in the manhole cover. The upper duct acting alone was almost $70 \%$ more effective than when the lower duct was opened. The ducts acting alone are similar to the single opening in the manhole cover although in this case air involved in the exchange must pass through a vertical cylinder of considerably greater length and diameter and containing a $90^{\circ}$ elbow. Various combinations of external duct(s) and opening(s) in the manhole cover considerably increased the ventilation rate beyond what was achievable by the openings in the manhole cover. Greatest rate of ventilation occurred using the two ducts alone or the lower duct and 48 openings in the manhole cover. Effective ventilation of the manhole in the absence of openings in the manhole cover can occur when both ducts are open. The lower duct and 12 openings in the manhole cover also provided effective ventilation.

Another way to examine the results of these tests is to consider ventilation effectiveness (efficiency). A single opening in the manhole cover is as effective (efficient) as two open ducts in the absence of openings in the manhole cover. This results from the large surface area of the ducts versus that of individual openings in the manhole cover. The openings in the manhole cover and duct(s) become more effective only when a large number of openings is combined with the lower duct or both ducts are used without openings. These results suggest that the combination of duct especially the lower duct and openings in the manhole cover or both ducts in the absence of openings can provide effective (efficient) ventilation of isolated subsurface structures. Further study could establish measures needed to optimize air flow induced by natural forces.

\subsection{Wiegand and Dunne, 1996}

Wiegand and Dunne (1996) reported on radon accumulation in subsurface structures in the British Telecommunications system and efforts to ventilate these structures by harnessing natural forces. The underground network contains deep shafts and tunnels up to $20 \mathrm{~m}$ deep with large internal volumes. There are, however, very few deep structures. Telecommunications vaults are typically around $3 \mathrm{~m}$ deep with an internal volume ranging from 4 to $20 \mathrm{~m}^{3}$. Cable ducts generally are unsealed and allow migration of gases and water between vaults. Part of this work involved a telecommunications vault having a depth of $2.5 \mathrm{~m}$ and volume of $11.5 \mathrm{~m}^{3}$. These structures typically contain water to half of the depth prior to preparation for entry. The manhole that provides access forms a neck-like structure with the body of the vault.

One component of the study involved dispersion of a dilute mixture of nitrous oxide $\left(\mathrm{N}_{2} \mathrm{O}\right)$ from the interior airspace by ventilation induced by natural forces during preparation for entry. The procedure involved introduction of a known volume of pressurized $\mathrm{N}_{2} \mathrm{O}$ into the airspace and mixing to constant concentration using a high-volume pump $(\mathrm{G}=0$, Equation 2). The manhole cover was then removed and the decrease in concentration over time measured in the airspace using a MIRAN 1A infra-red gas analyser. The MIRAN was located outside the structure. Surface wind speed ranged from 0.5 to $1.5 \mathrm{~m} / \mathrm{s}$ and gusted as high as $3 \mathrm{~m} / \mathrm{s}$.

While not stated in the method, allowing the mixture to calm prior to opening the manhole cover is essential to eliminate turbulence and momentum introduced by the mixing fan as artifacts to movement of the wind at grade level across the opening of the manhole. Sampling by the MIRAN is non-destructive and occurred through a recirculation loop powered by the internal sampling pump of the instrument. Sampling by this means has a potential influence on dispersion, although likely only small due to the large volume of the airspace.

Some of the tests (unassisted purging) utilized air movement across the open manhole as described above. Other tests (directed ventilation) utilized a vertical, suspended sheet of plastic positioned halfway across the manhole opening and projecting about $0.75 \mathrm{~m}$ above the surface to $0.5 \mathrm{~m}$ above the floor. This configuration diverted wind flow from the surface downward into the airspace of the vault and upward and out the other half of the opening. The latter is a type of once-through, push-pull system.

Wiegand and Dunne (1996) observed that the concentration of $\mathrm{N}_{2} \mathrm{O}$ decreased to $1 / 10$ of the starting level in about 30 minutes during unassisted ventilation, and 8 to 10 minutes during directed ventilation. Summary data for tests involving different types of vaults indicated considerably less variability between vaults for directed ventilation than for unassisted ventilation. Figure 5 reproduces the curve for unassisted ventilation provided by Wiegand and Dunne (1996) and provides the fitted curve and equation created by Microsoft Excel (Microsoft Office 2013, Microsoft Corporation, Redmond WA). Other than mentioning about the time needed for decrease of the starting concentration to $10 \%$ of the initial value, Wiegand and Dunne provided no further information. The equation for the curve has the form (Equation 5) when converted to concentration $(\mathrm{C})$ and time (t) for $\mathrm{y}$ and $\mathrm{x}$, respectively: 


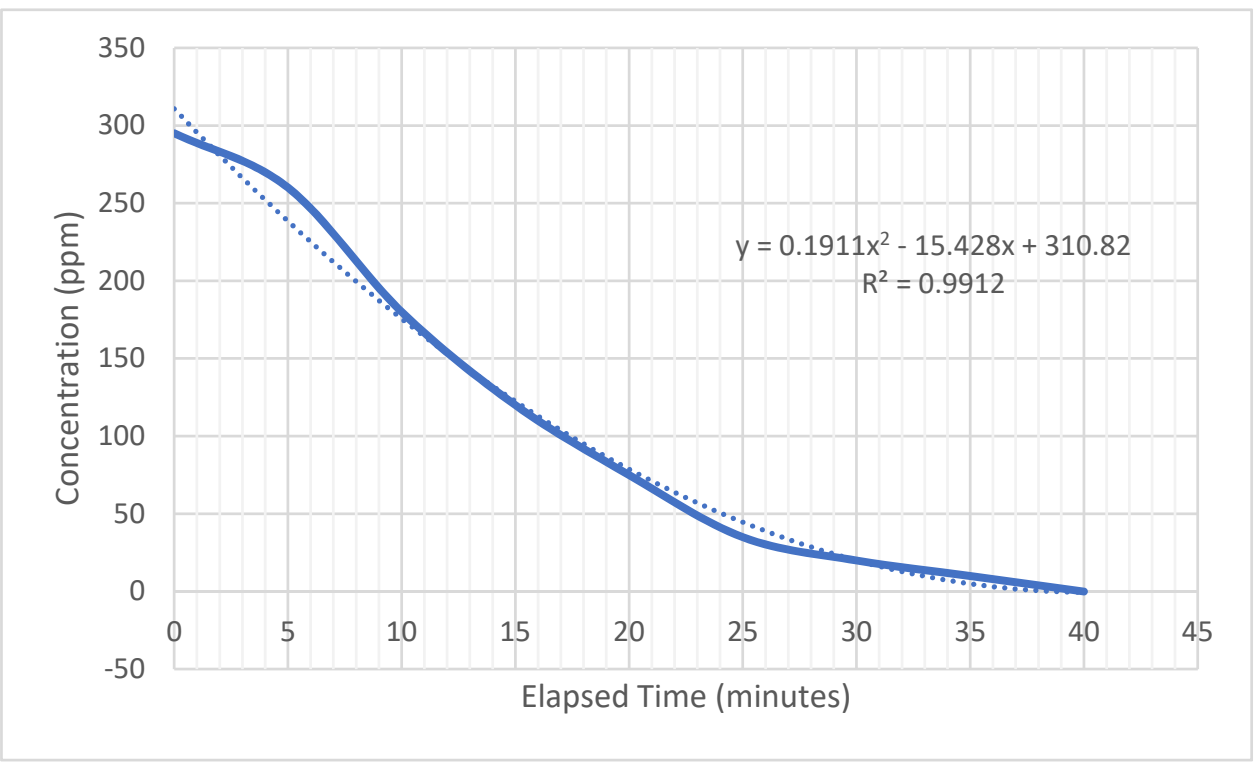

Figure 5. Decrease in concentration of $\mathrm{N}_{2} \mathrm{O}$ with time through an open manhole connected to a subsurface communications vault. Note that the atmosphere in the airspace emits undiluted from the opening at the start of the process

$$
\mathrm{C}=0.1911 \mathrm{t}^{2}-15.482 \mathrm{t}+310.82
$$

Dispersion of the contaminant through dilution induced by natural forces is a kinetic process. Kinetic processes are explored in chemical studies and exploited in chemical engineering through design of chemical reactors (Laidler, 1997) and also in ventilation (AIHA, 2009; Burgess et al., 1989). Kinetic processes also can occur during physical processes such as ventilation induced by natural forces as investigated here. Kinetic processes generally follow rate laws or equations. The $t^{0}$ term in Equation 5 corresponds to the $y$-intercept in the equation, $310 \mathrm{ppm}$ (parts per million). The $\mathrm{t}^{1}$ term represents a zero-order kinetic process and the $\mathrm{t}^{2}$ term, a first-order one. This view strongly suggests that dispersal of the test atmosphere of $\mathrm{N}_{2} \mathrm{O}$ through the open manhole occurred by zero and first order kinetic processes and that the zero-order process dominated and that the dispersion mostly depended on the concentration of contaminant. This also means that the well-mixed box model mostly applied during this process.

The experimental process utilized by Wiegand and Dunne was fundamentally different from that utilized by investigators at the Bureau of Mines and more real-world. In the former case, the generation rate was zero (Wiegand \& Dunne, 1996). That is, at the start of the test, the airspace of the structure contained all of the $\mathrm{N}_{2} \mathrm{O}$ to be removed by ventilation induced by natural forces as could occur during actual work. In the latter case, generation of the contaminant to be measured (the indicator gas) was continuous and at the rate needed to maintain equilibrium concentration (BM, 1936).

Wiegand and Dunne (1996) also examined incursion and removal of radioactive progeny of Radon-222 from the vaults under study. Radon (predominantly Radon-222) is a naturally occurring radioactive, inert gas formed by the radiolytic decay of Radium-226. Radon can diffuse through soil and migrate through cracks and fissures in rock whereas radium is immobilized. When trapped in sealed subsurface structures, accumulation of radon can occur. This part of the study involved active measurement Radon-222 and the progeny of Radon-222 using an instrument positioned just above the water level. These studies indicated that directed ventilation employed to disperse radon is effective in telecommunications vaults only to $3 \mathrm{~m}$.

\subsection{Gribble, 2009}

Gribble (2009) speculated about possible steps taken to engineer natural ventilation in the largest of the Egyptian tombs (KV5) in the Valley of the Kings. KV5 is horizontally-oriented and contains several chambers and many sub-chambers located at different levels (Weeks, 2006). Other tombs are vertically-oriented. Tombs in the Valley of the Kings have only a single entrance, hence flow-through ventilation was not technically possible by this choice of design. Yet, ventilation was essential for thermal comfort and for removal of airborne dust and other contaminants during the mining activity involved in construction. 
Gribble (2009) speculated that selective elevation of floors during construction induced natural airflow into and out of the airspace of the structure through the single opening. Natural ventilation was possible because of the thermal conditions imposed by the desert climate. Air in the desert cools rapidly at night and induces flow based on difference in temperature outside the tomb compared to the airspace inside. Effectiveness of the process depends on absence of turbulent mixing between the two flows (Gribble, 2009). Hence, measures to prevent or at the least to minimize mixing were essential.

\subsection{Theilacker and White, 2005}

Theilacker and White (2005) reported on a helium leak in the refrigeration system that cools magnets in a circular tunnel measuring $6.3 \mathrm{~km}$ in circumference in a research facility. Ventilation in the tunnel provides horizontal velocity of $3 \mathrm{~km} / \mathrm{h}(0.8 \mathrm{~m} / \mathrm{s})$. The tunnel is a long circular duct. The velocity profile is the same as in a duct at long distance from the fan (ACGIH, 2013). Monitoring data from oxygen sensors located at floor and ceiling level in the tunnel and at the top of the exit stairway indicated lowering of oxygen level throughout the cross-section of the tunnel following the leak as horizontal movement occurred. Mixing of the escaping gas with air in the cross-section leading to the lowering of concentration of oxygen countered the widely held presumption about stratification at ceiling level due to the low density of pure helium compared to air. Technical practitioners have also long believed about stratification even for dilute mixtures of gas and air. Movement of the helium around the tunnel measured as depression of oxygen required 4.75 hours.

Bench-scale tests using pure helium and pure sulfur hexafluoride trapped in a vertical cylinder closed at one end at ambient temperature in still air showed that gases more readily than expected diffused through the air column in the direction opposing buoyancy. Mixing time for dense gases such as sulfur hexafluoride was considerably greater than for gases of low density such as helium under the same circumstances. Gases such as nitrogen having density similar to air mix rapidly with air and do not readily form stratified mixtures.

\section{Discussion}

This review provides findings and analysis beyond those published in referenced reports and coalesces historically important knowledge from documents widely separated in time concerning ventilation induced by natural forces in subsurface structures entered through a manhole containing one or more openings. These reports contain discoveries previously lost in obscurity and provide the basis for further work to clarify and better explore underlying issues and questions. Work performed by investigators at the (US) Bureau of Mines established the fundamentals of ventilation of isolated subsurface structures induced by natural forces. This work occurred outdoors in a temperate climate over a period of several years. The first report established that the airspace of a subsurface structure containing a single opening on the top surface experiences two-way exchange with the atmosphere above (BM, 1936). Subsequent reports identified additional factors involved in ventilation of isolated subsurface structures induced by natural forces (BM, 1937; BM, 1938; BM, 1940).

Demonstration that two-way ventilation occurred through a single opening located in the manhole cover was a fundamentally important observation lost in obscurity from generations of practitioners in occupational health and safety. This knowledge provides the basis for further exploration of possibilities to reduce risk imposed by confinement of atmospheres in isolated subsurface structures starting with a change in design requiring all hatches and manhole covers to have at least one and preferably two defined pathways to enable exchange between the external atmosphere and the atmosphere in the airspace.

The means by which air exchange occurs is not intuitive and requires further elucidation. These are the subject of additional articles in this series (manuscripts submitted for review, not yet cited). Gribble (2009) highlighted the importance of subtle differences in the internal geometry of the isolated subsurface structure in promoting or hindering ventilation. Wiegand and Dunne (1996) showed that the atmosphere in the airspace of isolated subsurface structures rapidly emits outward into the surroundings when the manhole/hatch cover is partially or completely removed. McManus (2016) expanded considerably on work of investigators at the Bureau of Mines and obtained video showing the process of air exchange through opening(s) in the manhole cover and mixing in the airspace. Video recording techniques are the subject of an additional article in this series (manuscript submitted for review, not yet cited). Recent events have shown that emissions of this type can cause rapid and potentially fatal overexposures (Esswein et al., 2014; Harrison et al., 2016; Jordan, 2015; SRNL, 2014).

The incident reported by Theilacker and White (2005) highlighted the complexity of interactions between gas streams confined in structures and confirmed that what is presumed from theory to occur does not always occur in practice. Stratified layers of gases of different density mix more easily than liquids of different density and possible more so than vapor formed at the surface of an evaporating liquid. Dispersion of dense gases in air requires considerably more time than for dispersion of gases of low density under the same circumstances. In 
this context, use of ventilation induced by natural forces in isolated subsurface structures remains uninvestigated and unresolved.

What is apparent in the process of ventilation induced by natural forces is that inflow and outflow must occur through the same opening when one opening is present. Despite the possibility of interference in the process in the original investigations (BM, 1936; 1937; 1938, 1940) by non-natural factors such as slight pressurization of the indicator gas to create a push-pull system, Wiegand and Dunne (1996) were able to demonstrate the occurrence of the phenomenon in a structure containing a non-replenishing gas mixture through a full-sized manhole opening. Quantitative assessment of ventilation through the opening(s) in the manhole is the subject of an additional study in this series (manuscript submitted for review, not yet cited). The circumstances of the test performed by Wiegand and Dunne reflected real-world operations involving subsurface chambers at the time of opening the manhole cover or hatch to perform atmospheric testing necessitated by some types of instruments and insertion of duct to ventilate the airspace. Atmospheric testing instruments commonly used during confined space entry potentially will not respond to the atmospheric contamination in a particular situation. On-going continuous air exchange induced by natural forces considerably reduces the risk involved in these activities.

Inflow and outflow are no more apparent where more than one opening is available. Inflow and outflow could occur through all or only some openings. Openings could act co-operatively, neutrally or antagonistically. The additional finding about the number and area of openings in the manhole cover (BM, 1936, 1937, 1940) combined with additional analysis performed in this document showed the importance of ventilation effectiveness (efficiency). The most efficient number of openings is 1 to 2 . Efficiency of three or more openings is about the same as for larger numbers. This opens the question about efficiency versus number, whether two larger openings are more efficient than many smaller openings having the same total area.

Some isolated subsurface structures contain supplementary defined paths in addition to openings in manhole covers to assist ventilation induced by natural forces. The fourth report produced by investigators at the Bureau of Mines reinforced findings in previous reports and showed the importance of vertical position of openings into isolated subsurface structures when multiple openings are present (BM, 1940). The improvement may also reflect difference in temperature between interior and exterior air.

Airflow at or above the surface of the ground was another important factor measured but not discussed in these studies (BM, 1936, 1937, 1938, 1940). Airflow at the surface of the ground is the subject of an article in this series (manuscript submitted for review, not yet cited). The investigators at the Bureau of Mines were unable to quantify this impact but recognized its influence and importance. The current literature contains nothing on this subject relevant to the latter discussion. Wiegand and Dunne (1996) demonstrated the importance of surface air movement in self-ventilation of vaults accessed through manholes. These authors reported wind speeds ranging typically from 0.5 to $1.5 \mathrm{~m} / \mathrm{s}$ (100 to $300 \mathrm{ft} / \mathrm{min})$ and as high as $3 \mathrm{~m} / \mathrm{s}(600 \mathrm{ft} / \mathrm{min})$. Wind flow directed to the bottom of the airspace by an internal barrier projecting only slightly above the surface of the ground considerably increased the rate of removal of contamination. This concept, known as a wind tower when applied to ventilation of buildings, has been in use for centuries (Chand \& Bhargava, 1990; Hughes et al., 2012). While this concept has application in the ventilation of buildings, it is impractical as a means of ventilating isolated subsurface structures during entry and work because of inability to control delivery. This type of ventilation is non-directional and provides general supply and exhaust. It cannot be used effectively where directed supply flow or local exhaust ventilation is required. This type of ventilation can be very effective in purging these chambers during the period between entry and work.

Ventilation of isolated structure reduces accumulation of toxic and ignitable gases and vapors through on-going dilution. Airborne contamination occurs through metabolism by microorganisms on organic debris that enters the structure as well as evaporation of residual contents and volatile liquids that enter through spillage near the openings in the manhole cover or through surreptitious deliberate disposal into the structure. As well, in the absence of adequate ventilation, the internal atmosphere may become oxygen-deficient through chemical oxidation of susceptible materials and surfaces, adsorption, and biological oxidation through growth of microorganisms on organic debris that has entered the structure (McManus, 1998).

Ventilation of isolated subsurface structures in which an ignitable atmosphere can develop is more complex than in situations where worker exposure is the only consideration. Additional articles in this series report on this subject (manuscripts submitted for review, not yet cited). The concentrations involved in worker exposure are considerably less than those at which ignitability can occur (ACGIH, 2018; McManus, 1998). In order for an ignitable atmosphere to develop, the concentration of gas, vapor or mist must enter the Ignitable Range. The Lower and Upper Flammable Limits define the Ignitable Range within which a mixture is ignitable. In 
circumstances of rapid emission or low level of ventilation induced by natural forces, the concentration can exceed the Upper Flammable Limit. Such circumstances pose especial concern because dilution produced by exchange with the exterior atmosphere will eventually reduce the concentration into, through and finally below the Ignitable Range. If such circumstances occur rarely compared to those where the concentration never enters the Ignitable Range, then ventilation induced by natural forces during the period between entry and work is an important means of reducing and minimizing risk. Said differently, if control of worker exposure is achieved, so also is the potential for development of an ignitable atmosphere. If this is not reasonably possible, additional measures of control are required.

In the absence of installed ventilation in these structures, ventilation induced by natural forces provides the benefit of reducing the risk to workers and passersby from explosion and fire and to workers from exposure during contact with the internal atmosphere during preparation for entry. Based on previous discussion, such contact occurs when exchange of the atmosphere in the airspace of the structure with the external atmosphere begins following opening of the manhole cover or access hatch. This exposure occurs at grade prior to installation of portable ventilation equipment. Optimized ventilation of these structures maximizes to the extent possible the rate at which removal of contamination occurs. Optimized ventilation obtainable through harnessing natural forces is subject to further investigation.

The knowledgebase as described thus far is incomplete with regard to visualizing and understanding the mechanism(s) through which ventilation induced by natural forces is occurring. Understanding how ventilation induced by natural forces is occurring enables application of principles of design to optimize the process. Minimizing the risk imposed on workers during preparation and work in these structures depends on widespread application of the knowledge that does exist and elucidation of additional information not yet available through formal investigation. Ventilation induced by natural forces occurs routinely in these structures without cost. Hence, optimizing ventilation by natural forces offers great benefit at minimal cost and supplements other measures required during entry preparation and minimizes exposure because of inability of monitoring instruments to detect the presence of the contamination.

A number of fundamental questions require investigation in order to move forward this area of inquiry. An important question is how quickly does contamination in an isolated subsurface structure accumulate and disperse to background under the influence of natural forces given actual conditions following a contamination event? Another is, how many openings in a manhole cover are essential for prompt ventilation induced by natural forces under actual conditions? How large should the openings be? What geometric relationship should they have? Further articles in this series will explore some of these questions (manuscripts submitted for review, not yet cited).

Actions immediately available to OH\&S practitioners at this time based on information extracted from the articles discussed in this review include:

- ensuring that the access hatch or manhole providing entry into existing isolated subsurface structures not storing volatile toxic or ignitable substances and not regulated for other safety and environmental reasons has defined path(s) (one or more openings) for exchange of the atmosphere in the airspace with the external atmosphere.

- ensuring that the access hatch or manhole providing entry into structures to be installed in applications other than storing volatile toxic or ignitable substances and not regulated for other safety and environmental reasons has at least two openings that provide a defined path for exchange of the atmosphere in the airspace with the external atmosphere.

\section{Conclusions}

A detailed examination of the reports reviewed here provides the basis for determing the basic concepts involved in ventilation of isolated subsurface structures induced by natural forces. Combining the findings of the Bureau of Mines (BM, 1936; BM, 1937; BM, 1938; BM, 1940) and Wiegand and Dunne (1996), Gribble (2009) and Theilacker and White (2005) leads to some important findings. Air exchange occurs through large and small single and multiple openings located on the top surface of isolated subsurface structures. Reduction over time of contamination that develops in isolated subsurface structures through exchange between the external atmosphere and the airspace can minimize risk of preparation for entry. The practical upper limit of size of structures affected by natural ventilation could be substantial (major tombs in Egypt). The contaminated atmosphere in the structure emits at high concentration when partial or full opening of a manhole cover first occurs and decreases rapidly over time. Rapid decrease in concentration in the airspace of an isolated subsurface structure following opening indicates rapid entry and mixing and dilution by the external atmosphere into the airspace of the isolated 
subsurface structure. Airflow along the surface of the manhole or hatch cover exerts a major influence on air exchange between the external atmosphere and the airspace. Surface air flow exerted against a vertical panel dividing a manhole opening in half and protruding just above the ground and extending downward to just above the base of the structure has sufficient force to displace air from the other side. Practical limit of depth of this application is about $3 \mathrm{~m}$. Difference in temp between the exterior and interior and within the interior of a structure can exert a major influence on ventilation induced by natural forces. Slight differences in geometry inside isolated subsurface structures can exert major influence on ventilation induced by natural forces.

\section{Acknowlegements}

The financial support of CAPES (Coordenação de Aperfeiçoamento de Pessoal de Nível Superior), Brasilia, DF, Brasil and CNPq (Conselho Nacional de Desenvolvimento Científico e Tecnológico), formerly Conselho Nacional de Pesquisas, Brasilia, DF, Brasil (the Brazililian National Research Council) in pursuit of this work are gratefully acknowledged.

\section{Conflict of interests}

The authors declare that there is no conflict of interests regarding the publication of this paper.

\section{References}

ACGIH (American Conference of Governmental Industrial Hygienists). (2018). Threshold Limit Values for chemical substances and physical agents \& Biological Exposure Indices. Cincinnati (OH): American Conference of Governmental Industrial Hygienists.

AIHA (American Industrial Hygiene Association). (2009). In C. B. Keil, C. E. Simmons, \& T. R. Anthony (Eds.), Mathematical models for estimating occupational exposure to chemicals (2nd ed.). Fairfax, VA: American Industrial Hygiene Association.

BM (Bureau of Mines). (1923). In G. W. Jones, L. B. Berger, \& W. F. Holbrook (Eds.), Carbon monoxide hazards from house heaters burning natural gas (Technical Paper 337). Washington, DC: Department of the Interior, Bureau of Mines.

BM (Bureau of Mines). (1936). In G. W. Jones, W. E. Miller, J. Campbell, \& W. P. Yant (Eds.), Ventilation of manholes. 1. Effect of holes in the covers on natural ventilation (RI 3307). Washington, DC: Department of the Interior, Bureau of Mines.

BM (Bureau of Mines). (1937). In G. W. Jones, W. E. Miller, J. Campbell, \& W. P. Yant (Eds.), Ventilation of manholes. 2. Effect of the size of the manhole on natural ventilation (RI 3343). Washington, DC: Department of the Interior, Bureau of Mines.

BM (Bureau of Mines). (1938). In G. W. Jones, E. S. Baker, \& J. Campbell (Eds.), Ventilation of manholes. 3. Effect of wind velocity on natural ventilation (RI 3412). Washington, DC: Department of the Interior, U.S. Bureau of Mines.

BM (Bureau of Mines). (1940). In G. W. Jones, W. E. Miller, \& J. Campbell (Eds.), Ventilation of manholes. 4. Effect of vertical ducts in combination with openings in manhole covers on the natural ventilation (RI 3496). Washington, DC: Department of the Interior, U.S. Bureau of Mines.

Burgess, W. A., Ellenbecker, M. J., \& Treitman, R. D. (1989). Ventilation for control of the work environment. New York: Wiley-Interscience.

Chand, I., \& Bhargava, P. K. (1990). Studies on design and performance of a non-conventional system of natural ventilation in buildings. Solar \& Wind Technology, 7(2/3), 203-212.

Chen, Y. C., Bundy, D., \& Hoff, S. (1998). Modeling the variation of wind speed with height for agricultural source pollution control, ASHRAE-SF-98-26-2, The 1998 Winter Meeting, San Francisco, vol. 104. American Society of Heating, Refrigerating, and Air-Conditioning Engineers Transactions: Symposium, 104, 1685-1691. Retrieved from http://lib.dr.iastate.edu/cgi/viewcontent.cgi?article=1655\&context=abe_eng pubs

Esswein, E. J., Snawder, J., King, B., Breitenstein, M., Alexander-Scott, M., \& Kiefer, M. (2014). Evaluation of some potential chemical exposure risks during flowback operations in unconventional oil and gas extraction: preliminary results. Journal of Occupational and Environmental Hygiene, 11(10), D174-D184.

Gribble, D. (2009). Natural ventilation, harnessed by New Kingdom Egyptian tomb builders, may explain the changed floor levels in the Valley of the Kings tomb KV5. Tunnelling and Underground Space Technology, $24,62-65$. 
Harrison et al. (2016). Sudden Deaths Among Oil and Gas Extraction Workers Resulting from Oxygen Deficiency and Inhalation of Hydrocarbon Gases and Vapors-United States, January 2010-March 2015. Morbidity and Mortality Weekly Reports, 65, 6-9.

Hughes, B. R., Calautit, J. K., \& Ghani, S. A. (2012). The development of commercial wind towers for natural ventilation: A review. Applied Energy, 92, 606-607.

IEC (International Electrotechnical Commission). (1998). Wind turbine generator systems-Part 11: Acoustic noise measurement techniques (IEC 61400-11:1998). Geneva: International Electrotechnical Commission.

IEEE (Institute of Electrical and Electronic Engineers). (2015). Preventing and mitigating manhole events. White paper prepared by IEEE Insulating Conductors Committee-C34D. New York: Institute of Electrical and Electronic Engineers.

Jordan, T. (2015). Hydrocarbon exposures during tank gauging and sampling operations. NORA Oil and Gas Sector Council Meeting, Denver, CO. Retrieved from http://www.nationalstepsnetwork.com/docs_tank_ gauging/NORA_Oil_and_Gas_Council_Meeting_March2015.pdf

Laidler, K. J. (1997). Chemical kinetics (3rd ed.) Englewood Cliffs, NJ: Prentice Hall.

McManus, N. (1998). Safety and health in confined spaces. Boca Raton, FL: CRC Press.

McManus, T. N. (2016). Natural ventilation of isolated subsurface structures in the infrastructure. D.Sc. Dissertation. University Federal Fluminense, Programa de Pós-Graduação em Engenharia Civil, Niteroí, Brasil.

McManus, T. N., \& Haddad, A. N. (2018). Risk minimization in isolated subsurface structures through ventilation induced by natural forces. Safety Science, 102(2), 125-133.

Polonini, J. (2016). Bueiros transformam cidade em campo minado: 10 explosões que maracaram o Rio. Rio de Janeiro: o Globo, 13/07/2016. Retrieved from http://acervo.oglobo.globo.com/em-destaque/bueirostransformam-cidade-em-campo-minado-10-explosoes-que-marcaram-rio-19704742

Theilacker, J. C., \& White, M. J. (2005). Diffusion of gases in air and its effect on oxygen deficiency hazard abatement. Paper presented at 2005 Cryogenic Engineering Conference and International Cryogenic Materials Conference (CEC-ICMC 2005). 29 Aug-2 Sep 2005. Keystone, Colorado. Fermilab-Conf-05-635-AD.

Weeks, K. R. (2006). Theban mapping project, 1997-2006, Based at the American University in Cairo. Retrieved from http://www.kv5.com

Wiegand, K., \& Dunne, S. P. (1996). Radon in the workplace-a study of occupational exposure in BT underground structures. Annals of Occupational Hygiene, 40(5), 569-581.

\section{Copyrights}

Copyright for this article is retained by the author(s), with first publication rights granted to the journal.

This is an open-access article distributed under the terms and conditions of the Creative Commons Attribution license (http://creativecommons.org/licenses/by/4.0/). 